\title{
O TELETRABALHO NO CONTEXTO DO ENSINO A DISTÂNCIA
}

\author{
FRANCA/SP JULHO/2018
}

\author{
Maria Rafaela Junqueira Bruno Rodrigues - FDF / Fatec - mrjunque@gmail.com \\ Angelo Luiz Cortelazzo - Unicamp - alcortelazzo@hotmail.com \\ Dilermando Piva Junior - Fatec / CPS - pivajr@gmail.com
}

Tipo: Investigação Científica (IC)

Natureza: Descrição de Projeto em Andamento

Categoria: Suporte e Serviços

Setor Educacional: EDUCAÇÃO SUPERIOR

\begin{abstract}
RESUMO
Na mesma proporção em que há a difusão da Educação a Distância no país, há o aumento dos trabalhadores envolvidos no seu processo estrutural nas mais diversas funções, muitas das quais desenvolvidas como "teletrabalho". Tal atividade laboral não estava amparada pela legislação, principalmente no que se refere à sua prática na condição de trabalho home office ou como anywhere office. A reforma trabalhista, realizada pela Lei no 13.467/2017, regulamentou o teletrabalho, introduzindo na seara do Direito do Trabalho uma nova modalidade de trabalhador sem garantir, no entanto, a certeza de que o aparato legislativo vigente a partir de sua entrada em vigor, será suficiente para trazer a segurança jurídica necessária ao trabalhador em geral ou do ensino. Assim, o presente trabalho analisou o disposto na nova legislação sobre teletrabalho e a sua relação com as funções laborais presentes na maior parte dos cursos a distância, a partir da produção de material didático instrucional ou do acompanhamento ao discente que ocorre fora das dependências da Instituição de Ensino Superior responsável por sua produção e disponibilização online. Em que pese o avanço da introdução desse novo modo de relação entre empregado e empregador, ainda são notadas diversas lacunas, em parte por conta do fato de que a lei é recente, em parte porque ainda não foi estabelecida jurisprudência que traga a necessária segurança jurídica ao instituto do teletrabalho.
\end{abstract}

Palavras-chave: Educação a distância; Teletrabalho; Reforma trabalhista. 


\section{Introdução}

A sociedade e suas concepções com relação à vida humana têm mudado de maneira significativa e hoje, não há como conceber o trabalho, a educação, a tecnologia, ou a ciência, como outrora. Tal realidade tem forçado a mudança legislativa em todos os âmbitos em que há afetação jurídica e, desta forma, também nas relações trabalhistas.

Não há um único fator determinante para tais mudanças, que são fruto de uma gama de situações sociais, de cunho econômico, político, cultural, científico e tecnológico, que envolvem os relacionamentos humanos atingindo, portanto, direitos e obrigações.

Essas situações sociais acabaram levando ao surgimento de novas formas de trabalho, denominadas inicialmente como "home work", "home office", "anywhere office" etc. que afetaram as relações laborais e levaram à necessidade de estabelecer conceitos, direitos e obrigações advindos dessa nova relação trabalhista, o que veio a ocorrer, recentemente, com a introdução do "teletrabalho" na legislação brasileira.

Assim, o presente trabalho teve como objetivo analisar a legislação recentemente aprovada e as atividades normalmente necessárias para a produção e uso de material didático ou instrucional especialmente elaborado em ambientes diversos e que são amplamente utilizados em cursos desenvolvidos a distância.

Para atingir o objetivo proposto, foram analisadas as alterações introduzidas na legislação trabalhista em 2017, realizando-se também uma discussão de sua efetiva aplicabilidade no cotidiano dos profissionais inseridos no contexto da educação a distância, uma vez que a recente promulgação da legislação não levou, ainda, a uma posição jurisprudencial ou tendência dos Tribunais que representam o Poder Judiciário.

\section{Resultados e Discussão}

A recente alteração havida na legislação trabalhista, introduzida na Consolidação das Leis do Trabalho - CLT através da Lei no 13.467/17, a respeito das formas de trabalho que são o resultado da inovação tecnológica introduzida nos meios de produção e inicialmente denominadas como "home work", "home office", "anywhere office" etc, atualmente pela legislação referida como teletrabalho, trouxe sua regulamentação, no entanto, não se pode dizer que esta atenderá, de forma eficiente às necessidades dos trabalhadores que exercem esse tipo de atividade laboral. Dentro desse contexto, 
permeou a discussão levantada no presente trabalho, ou seja, a realização de uma análise dos termos legais para verificação de sua efetiva aplicabilidade no cotidiano desses profissionais que realizam essa espécie laboral de trabalho no contexto da educação a distância. No entanto, cabe salientar-se que diante de sua recente inserção no contexto legal, não se pode apontar resultados efetivamente práticos, pois, ainda não há uma posição jurisprudência ou uma tendência dos Tribunais do Trabalho que possam comprovar sua efetividade.

\subsection{Características legais}

A competência para legislar sobre matéria de Direito do Trabalho e, portanto, de regulamentar profissões é disciplinada pela Constituição Federal de 1988, art. 22, I, deixando essa prerrogativa, de forma exclusiva, a cargo da União que a exerce através do Congresso Nacional.

A Lei no 13.467, de 13 de julho de 2017, alterou sensivelmente a Consolidação das Leis do Trabalho - CLT, com a finalidade de adequar essa legislação às novas relações de trabalho (BRASIL, 2017).

Dentre as alterações introduzidas, destaca-se a inserção do "teletrabalho", modalidade que ganhou um Capítulo específico, denominado IIA - Do Teletrabalho, com cinco novos artigos: 75-A até 75-E. Para a criação desse novo Capítulo, o tema foi excluído do Capítulo II, que trata da duração e da jornada do trabalho, com a inclusão de um novo inciso em seu art. 62 (BRASIL/CLT, 2017, p.13), dado que o teletrabalho se configura em modalidade onde não faz sentido o estabelecimento de jornada, horários préestabelecidos etc.

No novo Capítulo II-A, o art. 75-A, introduz a prestação de serviços pelo empregado em regime de teletrabalho, enquanto que o seguinte, $75-B$, assim o define: "considera-se teletrabalho a prestação de serviços preponderantemente fora das dependências do empregador, com a utilização de tecnologias de informação e de comunicação que, por sua natureza, não se constituam como trabalho externo". (BRASIL/CLT, 2017, p.15)

Ressaltou o referido estatuto legal, no seu parágrafo único, que "o comparecimento às dependências do empregador para a realização de atividades específicas que exijam a presença do empregado no estabelecimento não descaracteriza o regime de teletrabalho".

Embora a legislação tenha o cuidado de definir o que é o teletrabalho, não cuidou de 
mencionar suas espécies, restando à doutrina se preocupar em indicá-las, o que acaba por trazer divergências, como ocorre nas obras de Estrada $(2014$, p.18) e Chiarella (2017, p.33), por exemplo.

Há que se ter cautela ao estabelecer um rol para as espécies de teletrabalho, pois se isso for taxativo, como bem mencionou Álvaro Mello (2018, p.1), "não é apenas o Home Office, é qualquer trabalho realizado à distância. Todos somos teletrabalhadores hoje, com smartphones conectados 24 horas ao e-mail, com computadores pessoais". Entretanto, podem existir muitas situações em que essa prática não se configure como um teletrabalho, mas apenas como uma maneira mais moderna de encaminhamento de comunicações a serem vistas, analisadas e desenvolvidas durante a jornada de trabalho, descaracterizando dessa forma, a afirmação do autor citado.

Em que pesem as divergências doutrinárias, a Organização Internacional do Trabalho OIT destaca que o teletrabalho é a "forma de trabalho efetuada em lugar distante do escritório central e/ou do centro de produção, que permita a separação física e que implique o uso de uma nova tecnologia facilitadora da comunicação" (DI MARINO, 2001, p.11), sendo este citado de várias maneiras, dependendo do idioma adotado. Assim, o teletrabalho pode ser conhecido como: telework, telecommuting ou e-work (inglês), telelavoro (italiano), teletrabajo (espanhol), telependulaire (francês), havendo ainda sua referência nas expressões networking (trabalho em rede), remoteworking (trabalho a distância), flexibleworking (trabalho flexível), home working (trabalho em casa), home office (escritório em casa) e anywhere office (escritório em qualquer lugar).

De qualquer forma, o teletrabalho se acha atualmente disciplinado devendo ser observada a legislação brasileira, que o admite e o conceitua, apesar de não o classificar ou apontar suas espécies, como já mencionado na Consolidação das Leis do Trabalho - CLT

$\mathrm{O}$ art. $75-\mathrm{C}$ da CLT, determina que a prestação de serviços na modalidade do teletrabalho deverá constar expressamente do contrato individual de trabalho, que especificará as atividades que serão realizadas. Dispõe ainda, no seu parágrafo primeiro, que poderá ser realizada a alteração entre regime presencial e de teletrabalho, desde que haja mútuo acordo entre as partes, registrado em aditivo contratual. A realização de tal aditamento pressupõe a existência de um contrato individual de trabalho presencial, que virá sofrer modificação para o teletrabalho por convenção das partes. A legislação permite, também, a possibilidade inversa e, nesse caso, se dá em conformidade ao $\S^{\circ}$ do artigo citado. 
Percebe-se, que as regras para criar a estrutura necessária para se efetuar o teletrabalho foram relegadas à convenção entre as partes. Assim, o art. 75-D estabelece que as disposições relativas à responsabilidade pela aquisição, manutenção ou fornecimento dos equipamentos tecnológicos e da infraestrutura necessária e adequada à prestação do trabalho remoto, bem como o reembolso de despesas arcadas pelo teletrabalhador, deverão estar previstas no contrato escrito e não podem integrar a remuneração do empregado.

Com relação à saúde do teletrabalhador, a legislação tão somente se limitou a indicar que o empregado terá por obrigação assinar um termo de responsabilidade (§único, do art. 75-E), comprometendo-se a seguir as instruções fornecidas pelo empregador, que deverão ser realizadas de maneira expressa, o que pressupõe que sejam realizadas por escrito e ostensivas, com a finalidade de precaver-se e evitar doenças e acidentes de trabalho (art. 75-E).

Neste contexto, a emergência legal de se regulamentar o teletrabalho, representou uma forma flexível (FRIEDMAN, 2007, p.53), que depende do estabelecimento de aspectos importantes da prática dessa atividade laboral do convencionado entre empregador e empregado, sob pena de haver prejuízo aos direitos dos trabalhadores dessa modalidade, o que se constatará somente ao longo do tempo

Há que se levar em consideração que o novo Inciso do art. 62 já citado, excluiu esse teletrabalhador das regras de CLT quanto à jornada de trabalho, não havendo para o mesmo, limites quanto às horas diárias ou semanais de trabalho, nem registro ou controle de horários o que, a longo prazo, poderá vir a contribuir para a falta de saúde desse trabalhador.

Como mencionado por Raimundo Simão de Mello (2018, p.152): "para o interesse da empresa há controle para efeito de gestão da força de trabalho, mas não haverá contrapartida sobre a proteção do trabalho. No tocante às condições de saúde e segurança no trabalho, a única obrigação atribuída ao empregador é a de 'instruir os empregados, de maneira expressa e ostensiva, quanto às precauções a tomar' (Art. 75-E)."

Dessa forma pode-se dizer que houve uma displicência legal com relação a um direito do trabalhador, quanto a sua saúde e a sua segurança, remetendo esta responsabilidade ao próprio trabalhador.

As consequências poderão ser nefastas ao longo do tempo, pois certamente irão 
contribuir para que haja o aumento de doenças e acidentes de trabalho, fruto de um ambiente laboral que não se acha adequado às necessidades do trabalhador, sem observância de regras ergonômicas, sem controle da intensidade do trabalho, da quantidade e ritmo de trabalho, dentre outros, o que fere o princípio constitucional maior que é o respeito à dignidade da pessoa humana.

\subsection{Características do trabalho EaD}

Os cursos estruturados para desenvolvimento a distância, em geral, tendem a necessitar do teletrabalhador.

Para a elaboração de material instrucional, desenvolvimento e autoria de conteúdos das atividades curriculares, apesar de possível, não há necessidade de utilização das instalações físicas da Instituição proponente do curso. Pelo contrário, ao menos em parte do trabalho, a reclusão do autor em sua residência pode, não apenas economizar um tempo precioso que é gasto no deslocamento do mesmo, desse local até a Instituição de ensino, como também tornar a produção mais eficiente e rápida, por poder ocorrer em espaços de tempo ligados à conveniência do autor. Além disso, possibilita a contratação de especialistas mais adequados e que residem em locais distantes o bastante para impedir o seu deslocamento frequente ao local onde funciona o centro gerador da produção do material didático.

Tais características são decorrentes da própria natureza dos cursos a distância, mas podem também ser existentes em cursos presenciais que realizem a produção de material específico para os seus estudantes.

No desenvolvimento das atividades a distância, há uma outra atividade que pode se configurar como um teletrabalho: as atividades de mediação ou tutoria a distância. Tais profissionais, que podem se concentrar nas instalações da Instituição de ensino podem, também, exercer suas atividades em locais e tempos diversos, sem com isso perderem sua eficiência e eficácia para o desenvolvimento da atividade curricular em tela.

Videoaulas, teleaulas, teleconferências e outras atividades também podem ser desenvolvidas na Instituição de Ensino ou em estúdios ou instalações especializadas a esse tipo de tarefa em outros locais, configurando teletrabalho.

Finalmente, processos de avaliação e correção das atividades programadas também 
podem ser desenvolvidos em locais e tempos diversos daqueles estabelecidos em um contrato de jornada tradicional e se configurar em teletrabalho.

Essas características rapidamente levantadas, assim como muitas outras já existentes e em andamento para atendimento dos projetos pedagógicos de curso, juntamente com o respeito aos direitos do autor, com certeza levarão a uma série de novas relações de trabalho entre empregados e empregadores no setor educacional e, portanto, merecem um acompanhamento que possibilite que não haja prejuízos aos direitos e deveres dos profissionais em geral, e da educação em particular.

\subsection{Aspectos jurisprudenciais para reflexão}

Apesar de ser um instituto recentemente regulamentado, já houve uma decisão do Tribunal Regional do Trabalho, quando suscitado o direito de horas extras. Por meio dela se pode pensar a respeito das horas extras, uma lacuna caracterizada pela ausência de regulamentação legal envolvendo o teletrabalho, de maneira a indicar haver direitos a serem respeitados, mas que são ainda, obscuros quanto aos seus resultados.

TRT-3- RECURSO ORDINARIO TRABALHISTA RO00101320520165030178 0010132-05.2016.5.03.0178 (TRT-3). Data de publicação: 13/03/2017. Ementa: hORAS EXTRAS. TELETRABALHO. Como corolário do desenvolvimento das tecnologias de informação e comunicação, constata-se a evolução nos modos de prestação do trabalho e, num misto de vantagens e desvantagens sob a ótica jus trabalhista, surgiu o teletrabalho. Assim, havendo a menor possibilidade de aferição da jornada trabalhada por esse empregado, ainda que de forma mista (em ambiente institucional e home office), as horas prestadas em sobrejornada devem ser devidamente remuneradas, na forma do art. $7^{\circ}$, XVI , da Constituição da República.

Apesar de recentemente regulamentado, o instituto do teletrabalho criou expectativas para vários trabalhadores que exercem suas funções por meio dessa modalidade, inclusive aqueles que trabalham com o ensino a distância, devendo ser observadas as tendências jurisprudenciais, costumes, os princípios gerais de direito e equidade, como determinado pelo art. $4^{\circ}$, da Lei de Introdução às Normas do Direito Brasileiro. 


\section{Considerações Finais}

A reforma trabalhista inseriu o teletrabalho no contexto do Direito Trabalhista, por meio da Lei $n$ ㅇ 13.467 de 13 de julho de 2017, que adicionou, revogou, ou alterou uma série de artigos da Consolidação das Leis do Trabalho - CLT.

Os artigos introduzidos para definir e regulamentar o teletrabalho dizem respeito à definição e à relação entre empregador e empregado, mas ainda há muitas lacunas a serem tratadas que a jurisprudência e a evolução dessa forma de atividades contribuirão para o aprimoramento do que foi, neste momento, adicionado à CLT.

Apesar disso, a referida regulamentação se apresenta como um avanço, uma vez que o teletrabalho desenvolvido especialmente em cursos a distância estava acéfalo de uma legislação que o regulamentasse e garantisse os direitos dos profissionais nele envolvidos.

\section{Referências}

BRASIL. 2017. Lei no 13.467, de 13 de julho de 2017. Disponível em http://www.planalto.gov.br/ccivil_03/_ato2015-2018/2017/lei/l13467.htm. Acesso em 12.05.2018.

BRASIL/CLT. 2017. Consolidação das leis do trabalho. Disponível em http://www.planalto.gov.br/ccivil_03/decreto-lei/Del5452.htm. Acesso em 12.05.2018.

CHIARELLA, José Roberto. A influência das Gerações Y e Z no Teletrabalho: Home Office, Anywhere Office e o Novo Modelo de Produção no Brasil e Argentina. Buenos Aires, Argentina: A4 Ideias Distribuciones, 2017.

ESTRADA, Manuel Martín Pino. Teletrabalho \& Direito: o Trabalho à Distância e sua Análise Jurídica em Face aos Avanços Tecnológicos. Curitiba: Juruá, 2014.

FRIEDMAN, Thomas. O mundo é plano: uma breve história do século XXI. Tradução: Cristiana Serra, S. Duarte e Bruno Casotti. Rio de Janeiro: Objetiva, 2007. 
DI MARINO, Vitorio. Promoting decent work: the high road to teleworking. Geneva, 2001, p.11. Disponível em: http://sidtu.org/SID-UNION-FILES/SID-PDF-DOCS/ILOTeleworking.pdf. Acesso em: 12.05.2018.

MELLO, Álvaro. Vá para casa. Revista Gestão \& Negócios. Disponível em: http://www.gestaoenegocios.digisa.com.br/gestao-motivacao/57/artigo293385-4.asp/. Acesso em: 12.05.2018.

MELLO, Raimundo Simão de. Impactos da reforma trabalhista sobre o meio ambiente do trabalho e a saúde dos trabalhadores. REVISTA DO ADVOGADO. AASP 75 anos. Reforma Trabalhista. № 137 - Março/2018. São Paulo: AASP Associação dos Advogados de São Paulo, 2018. 